\title{
PENGARUH TEKNIK RELAKSASI BENSON TERHADAP TINGKAT STRES PADA LANSIA DI RUANG RAWAT INAP RSU BHAYANGKARA TEBING-TINGGI
}

\author{
Deddy S Sagala \\ Dosen Prodi S1Keperawatan, STIKes Imelda, Jalan Bilal Nomor 52 Medan; \\ E-mail: deddyspsagala@gmail.com
}

\begin{abstract}
ABSTRAK
Relaksasi Benson merupakan pengembangan metode respon relaksasi pernafasan dengan melibatkan faktor keyakinan pasien, yang dapat menciptakan suatu lingkungan internal sehingga dapat membantu pasien mencapai kondisi kesehatan dan kesejahtraan yang lebih tinggi (Benson \& Proctor 2000, dalam Purwanto, 2014). Kelebihan latihan tehnik relaksasi dari pada latihan yang lain adalah latihan relaksasi lebih mudah dilakukan bahkan dalam kondisi apapun serta tidak memiliki efek samping apapun (Deleon, 1999). Disamping itu kelebihan dari tehnik relaksasi lebih mudah dilaksanakan oleh pasien, dapat menekan biaya pengobatan, dan dapat digunakan untuk mencegah terjadinya stres. Sedangkan kita tahu pemberian obat-obatan kimia dalam jangka waktu lama dapat menimbulkan efek samping yang dapat membahayakan pemakainya seperti gangguan pada ginjal (Yosep, 2015). Jenis penelitian yang di gunakan pada penelitian ini adalah Quasi Eksperimental Desaign dengan rancangan one group pretensposttenst.Populasi dalam penelitian ini adalah seluruh klien lansia yang menjalani rawat inap di RSU Bhayangkara Tebing-tinggi. Jumlah populasi pasien lansia bulan Maret -2017 sebanyak 43 orang.Teknik pengambilan sampel menggunakan teknik non probability sampling, metode pengumpulan data dengan intervensi secara langsung menggunakan lembar observasi pengukuran tingkat stress yang diperoleh dari hasil Depression Anxiety Stres Scale (DASS) yang sudah di modivikasi oleh peneliti yang terdiri dari 14 pertanyaan yang bersifat tertutup Analisa data dengan menggunakan uji wilcoxon Signed Ranks Test didapatkan selisih mean rank > 10; p>0.005 Hal ini menunjukkan ada pengaruh Tekhnik relaksasi benson Terhadap Tingkat Stress Pada Lansia yang Menjalani Rawat Inap di Rumah Sakit Umum Bhayangkara Tebing Tinggi Tahun 2017. Untuk itu diharapkan kepada Perawat dapat berperan dalam memaksimalkan hajat hidup lansia dengan cara pemberian perawatan secara holistik untuk meningkatkan kualitas kesehatan bagi populasi penduduk lansia (Gustiputrijayanti, 2016).
\end{abstract}

Kata kunci: Teknik Relaksasi Benson, tingkat stres, lansia, rawat inap

\section{PENDAHULUAN}

Kantor Kementerian Koordinator Kesejahteraan Rakyat (KESRA) melaporkan , jika tahun 1980 Usia Harapan Hidup (UHH) 52,2 tahun dan jumlah lansia 7.998 .543 orang $(5,45 \%)$ maka pada tahun 2006 menjadi 19 juta orang $(8,90 \%)$ dan UHH juga meningkat (66,2 tahun). Pada tahun 2010 perkiraan penduduk lansia di Indonesia akan mencapai 23,9 juta atau 9,77 $\%$ dan UHH sekitar 67,4 tahun. Sepuluh tahun kemudian atau pada 2020 perkiraan penduduk lansia di Indonesia mencapai 28,8 juta atau 11,34 \% dengan UHH sekitar 71,1 tahun (Tjiptadinata Efendi, 2016)

Stres pada lansia dapat didefinisikan sebagai tekanan yang diakibatkan oleh stresor berupa perubahan-perubahan yang menuntut adanya penyesuaian dari lansia.
Tingkat stres pada lansia berarti pula tinggi rendahnya tekanan yang dirasakan atau dialami oleh lansia sebagai akibat dari stresor berupa perubahan-perubahan baik fisik, mental, maupun sosial dalam kehidupan yang dialami lansia (Indriana, 2010). Beberapa faktor-faktor yang mempengaruhi stres pada lansia meliputi, kondisi kesehatan fisik, kondisi psikologi, keluarga, lingkungan, pekerjaan (Fitria, 2015).

Adanya penurunan pada kondisi lansia, maka akan mengalami perubahan aspek psikologis yang berkaitan dengan keadaan kepribadian Lansia. Karakteristik Lansia yang di panti werdha dengan Lansia yang bersama keluarga memiliki perbedaan karakteristik, karakteristik ini berpengaruh pada perilaku yang dilakukan sehari-hari. Karakteristik stres lansia di panti werdha 
dipengaruhi lingkungan internal. Lingkunga $\mathrm{n}$ internal dipersepsi individu berupa gejala dan kekecewaan atau kemarahan pada anak atau keluarga. Seperti diketahui lansia seharusnya berkumpul dengan keluarga tetapi malah ditempatkan pada panti jompo dan terdapat pula yang menginginkan untuk tinggal karena tidak mempunyai tempat tinggal dan keluarga, perasaan jauh dari keluarga dan rasa terbuang dari orang-orang yang disayangi itulah yang membuat lansia merasa dirinya tersisih. Sehingga lansia yang ditempatkan di panti akan mengalami perubahan prilaku seperti mudah merasa kesal, tidak sabaran, pemarah, gelisah, pendiam dan perubahan strategi koping dengan kondisi tersebut maka lansia akan mudah mengalami stres (Rosita, 2014).

Salah satu upaya untuk mengatasi stres adalah dengan metode relaksasi. Hal itu karna dalam relaksasi terkandung unsur penenangan diri. Teknik ini disebutnya relaksasi Benson yaitu suatu prosedur untuk membantu individu berhadapan pada situasi yang penuh stres dan usaha untuk menghilangkan stress (Dalimartha 2008). Relaksasi ada beberapa macam (Miltenbarge $r$, 2004) mengemukakan ada 4 macan relaksasi yaitu relaksasi otot (progressive muscle relaxation), pernafasan (diaphragmat ic breathing), meditasi (attention-foccusing exercises), dan relaksasi prilaku (behavioral relaxation training).

Relaksasi Benson merupakan pengemb angan metode respon relaksasi pernafasan dengan melibatkan faktor keyakinan pasien, yang dapat menciptakan suatu lingkungan internal sehingga dapat membantu pasien mencapai kondisi kesehatan dan kesejahtraa $\mathrm{n}$ yang lebih tinggi (Benson \& Proctor 2000, dalam Purwanto, 2014). Kelebihan latihan tehnik relaksasi dari pada latihan yang lain adalah latihan relaksasi lebih mudah dilakukan bahkan dalam kondisi apapun serta tidak memiliki efek samping apapun (Deleon, 1999). Disamping itu kelebihan dari tehnik relaksasi lebih mudah dilaksanakan oleh pasien, dapat menekan biaya pengobatan, dan dapat digunakan untuk mencegah terjadinya stres. Sedangkan kita tahu pemberian obat-obatan kimia dalam jangka waktu lama dapat menimbulkan efek samping yang dapat membahayakan pemakainya seperti gangguan pada ginjal (Yosep, 2015).

Proses pernafasan yang tepat merupakan penawar stres. Proses pernafasan merupakan proses masuknya $\mathrm{O} 2$ melalui saluran nafas kemudian masuk keparu dan diproses kedalam tubuh, kemudian selanjutnya diproses dalam paruparu tepatnya di bronkus dan diedarkan keseluruh tubuh melalui pembuluh vena dan nadi untuk memenuhi kebutuhan akan O2. Apabila O2 dalam otak tercukupi maka manusia berada dalam kondisi seimbang. Kondisi ini akan menimbulkan keadaan rileks secara umum pada manusia. Perasaan rileks akan diteruskan ke hipotalamus untuk menghasilkan Corticotropin Releasing Factor (CRF). Selanjutnya CRF merangsang kelenjar di bawah otak untuk meningkatkan produksi Proopioidmelanocortin (POMC) sehingga produksi enkephalin oleh medulla adrenal meningkat. Kelenjar dibawah otak juga menghasilkan ßendorphin sebagai neurotransmitter yang mempengaruhi suasana hati menjadi rileks. Meningkatnya enkephalin dan $\beta$ endorphin kebutuhan tidur akan terpenuhi dan lansia akan merasa lebih rileks dan nyaman (Taylor, 2001 dalam Risnas 2015).

Hasil studi pendahuluan yang dilakukan oleh peneliti pada tanggal 8 Maret 2017 di Unit Rawat inap RSU Bhayangkara TebingTinggi, diperoleh informasi dari pegawai yang bertugas mengatakan bahwa kapasitas Unit Rawat inap RSU Bgayangkara TebingTinggi adalah 120 dan sekarang dihuni sebanyak 40 lansia dengan rentang usia 6090 tahun yang tersebar pada 15 ruangan. Hasil observasi dan wawancara pada 10 lansia, didapatkan hasil: 6 lansia diantaranya mengalami stres yaitu: 2 orang mengeluh penyakitnya tidak kunjung sembuh, susah tidur, sulit fokus terhadap apa yang dikerjakan dan terlihat tidak bersemangat, 3 orang mengeluh kangen dengan suasana di 
rumah, jarang dijenguk keluarga, terkadang memilih sendiri dan menangis saat teringat dengan keluarga, dan 1 orang mengalami stroke, merasa kebingungan saat ditanya (pelupa), tidak bersemangat dan 4 lansia diantaranya tidak mengalami stres. Upaya yang dilakukan perawat dalam menangani masalah ini adalah dengan kolaborasi memberikan obat-obatan seperti obat penenang. Berdasarkan latar belakang tersebut, dapat dirumuskan masalah penelitian sebagai berikut "adakah Pengaruh Teknik Relaksasi Benson terhadap tingkat stres pada lansia di ruang rawat inap RSU Bhayangkara Tebing-Tinggi Tahun 2017.

\section{Rumusan Masalah}

Berdasarkan fenomena diatas dapat dirumuskan masalah penelitian yaitu "Bagaimana Pengaruh Teknik Relaksasi Benson Terhadap Penurunan Tingkat Stres Pada Lansia Yang Menjalani Rawat Inap Di Rumah Sakit Umum Bhayangkara TebingTinggi ?

\section{Tujuan Penelitian}

Tujuan penelitian ini adalah untuk mengidentifikasi Bagaimana Pengaruh Teknik Relaksasi Benson Terhadap Penurunan Tingkat Stres Pada Lansia Yang Menjalani Rawat Inap Di Rumah Sakit Umum Bhayangkara.

\section{Manfaat Penelitian}

1. Bagi Lansia beserta keluarga

Sebagai masukan pengetahuan untuk memberikan rasa nyaman dan mengatas i rasa stress akibat hospitalisasi yang cukup lama.

2. Bagi Rumah Sakit

Hasil penelitian ini dapat dijadikan informas bagi pihak pelayanan kesehata n untuk mengidentifikasi Pengaruh Tehnik Relaksasi Benson Terhadap Penurunan Tingkat Stress Pada Lansia Yang Menjalani Rawat Inap Di Rumah Sakit Umum Bhayangkara TebingTinggi.

3. Bagi Pendidikan Keperawatan
Bahan masukan pengembangan dan keterampilan yang berharga bagi peneliti, dalam menerapkan pengalama $\mathrm{n}$ ilmiah untuk penelitian dimasa mendatang. Selain itu juga menyediaka $\mathrm{n}$ informasi mengenai pengetahuan dan sikap perawat dalam penggunaan Tehnik Relaksasi Benson Terhadap Penurunan Tingkat Stress Pada Lansia Yang Menjalani Rawat Inap Di Rumah Sakit Umum Bhayangkara TebingTinggi.

4. Bagi Penelitian Keperawatan

Menambah informasi bagi penelitian keperawatan mengenai peran perawat dalam penerapan Tehnik Relaksasi Benson Terhadap Penurunan Tingkat Stress Pada Lansia Yang Menjalani Rawat Inap, sehingga memberikan ide bagi penelitian keperawatan selanjutnya

\section{METODE \\ Jenis Penelitian}

Jenis penelitian yang di gunakan pada penelitian ini adalah Quasi Eksperimental Desaign dengan rancangan one group pretens-posttenst. One group pretensposttenst adalah rancangan yang tidak ada kelompok bandingan (kontrol) namun sudah dilakukan observasi pertama (pre test) yang memungkinkan peneliti dapat menguji perubahan yang terjadi setelah adanya eksperiment (post test) (Notoatmodjo, 2013). Sugiono (2014) menambahkan bahwa pada rancangan one group pretestpostest terdapat pretest (01) sebelum di beri perlakuan (X) dan kemudian di lakukan pengukuran atau postest (02) setelah perlakuan, sehingga hasil perlakuan dapat diketahui lebih akurat, karena dapat membandingkan dengan adanya sebelum diberikan perlakuan.

Perlakuan yang diberikan berupa interpensi relaksasi benson dengan pengukuran (01 dan 02) yang di lakukan adalah tingkat stress pada lansia di RSU Bhayangkara Tebing-tinggi. Alasan penelitian memilih jenis penelitian ini adalah untuk mengetahui pengaruh 
intervensi berupa terapi relaksasi terhadap tingkat stress tanpa membandingkan dengan variabel kontrol. Untuk menentukan bahwa hasil postest yang di peroleh pada akhir penelitian merupakan akibat dari intervensi, maka peneliti membatasi karakteristik responden dengan beberapa kriteria. Rancangan penelitian dapat di gambarkan dalam bagan berikut :

Gambar 1. Rancangan penelitian pra eksperimental pre-test dan post-test group design Pre test Perlakuan Post test

\begin{tabular}{|ccc}
\hline $\mathrm{O}_{1}$ & $\mathrm{X}$ & $\mathrm{O}_{2}$ \\
\hline
\end{tabular}

Keterangan:

$\mathrm{X}$ : perlakuan

$\mathrm{O}_{1} \quad$ : pre test (tingkat stress sebelum intervensi terapi benson).

$\mathrm{O}_{2} \quad$ : post test (tingkat stress sesudah intervensi terapi benson).

\section{Populasi Penelitian}

Populasi dalam penelitian adalah sekelompok subyek yang menjadi sasaran penelitian (Notoatmodjo, 2013). Populasi dalam penelitian ini adalah seluruh klien lansia yang menjalani rawat inap di RSU Bhayangkara Tebing-tinggi. Jumlah populasi pasien lansia bulan Maret -2017 sebanyak 43 orang.

\section{Teknik Penentuan Sampel}

Teknik pengambilan sampel dilakukan dengan menggunakan teknik non probability sampling yaitu teknik yang tidak memberika $\mathrm{n}$ kesempatan yang sama bagi anggota populasi untuk dapat di pilih menjadi sampel. Pendekatan teknik non probabiliti sampling yang di gunakan adalah purposive sampling. Tehnik ini merupakan teknik pengambilan sampel dengan pertimbangan tertentu sesuai yang di kehendaki peneliti sendiri (Setiadi, 2013).

\section{Sampel Penelitian}

Sampel adalah sebagian yang dimbil dari keseluruhan objek yang di teliti dan di anggap mewakili seluruh populasi (Notoatm odjo, 2013). Jumlah sampel untuk penelitian Quasi Eksperimenbisa minimal 30 responde n (Sugiono, 2014). Adapun kriteria penentua n sampel dalam penelitian ini yakni :

1. Kriteria Inklusi

a. Responden yang bersedia menjalani penelitian.

b. Responden yang menjalani rawat inap di RSU Bhayangkara Tebingtinggi.

c. Responden yang mengalami stress dan sedang menjalani rawat inap di RSU Bhayangkara Tebing-tinggi.

d. Responden yang tidak dalam pengobatan terapi.

2. Kriteria Eksklusi

a. Responden yang tidak bersedia diteliti.

b. Lansia yang mengalami permasalaha n pada sistem pernafasan (ASMA, PPOK, TBC, Pneumonia).

c. Lansia yang sementara mengkons umsi obat tidur, kopi alcohol dan susu hangat.

Berdasarkan tehnik sampling diatas, jumlah sampel yang terkumpul dalam penelitian ini berjumlah 28 lansia yang menjalani rawat inap di RSU Bhayangkara Tebing-tinggi.

\section{Lokasi dan Waktu Penelitian}

Penelitian ini di lakukan di Wilayah Kerja RSU Bhayangkara Tebing-tinggi. Penelitian ini dilakukan pada bulan April sampai Mei 2017. Waktu penelitian dihitung mulai dari pembuatan proposal sampai penyusunan laporan dan publikasi penelitian.

\section{Definisi Operasional}

Definisi operasional dalam penelitian ini terdiri dari dua variabel yaitu variabel indenpenden dan variabel dependen. Variabel indenpenden dalam penelitian ini adalah tehnik relaksasi benson, sedangkan variabel dependennya adalah tingkat stress pada lansia. 


\section{Pengumpulan Data Data primer}

Data primer adalah data yana diperoleh peneliti dari hasil pengukuran, pengamatan, survei, dan lain-lain ( Setiadi, 2013). Data primer pada penelitian ini adalah data hasil pengukuran tingkat stress yang diperoleh dari hasil kuisioner dalam penelitian ini menggunakan Depression Anxiety Stres Scale (DASS) yang sudah di modivikasi oleh peneliti yang terdiri dari 14 pertanyaan yang bersifat tertutup. Pada setiap peryataan subyek diminta untuk menjawab stiap pertanyaan yang sudah di tentukan yaitu sangat sering diberi skor 3, sering diberi skor 2, kadang diberi skor 1 dan tidak pernah diberi skor 0 . Pada tahab pengambilan data, peneliti datang ke ruangan subyek pada hari yang telah di tentukan sebelumnya dengan pihak ruangan rawat inap dan responden diminta untuk mengisi kuisioner yang telah disediakan. Pada saat pengambilan data, kepada sampel secara langsung sebelum dan setelah terapiyang dicatat menggunakan lembar observasi.

\section{Data sekunder}

Data sekunder adalah data yang diperoleh dari pehak lain, badan/instansi yang secara rutinmengumpulkan data (Setiadi, 2013). Data sekunder penelitian ini berupa data klien lansia yang terdaftar di wilayah kerja RSU Bhayangkara Tebingtinggi.

\section{Pengolahan dan Analisa Data}

Pengolahan data adalah langkahlangkah yang dilakukan dalam penelitian setelah data diperoleh dari instrumen atau pengumpulan data kemudian dilakukan penyusunan data, klasifikasi, hingga analisa adata (Notoatmodjo, 2013). Kegiatan dalam pengolahan dan analisa data adalah sebagai berikut :

1. Editing

Proses editing adalah pemeriksaan daftar pertanyaan yang diperoleh dari responden. Pemeriksaan daftar pertanyaan ini dapat berupa kelengkapan jawaban, keterbacaan tulisan, dan relevansi jawaban dari responden (Setiadi, 2013).

2. Coding

Coding adalah peroses mengubah data berbentuk kalimat atau huruf menjadi data angka atau bilangan. Pemberian kode pada suatu penelitian akan membantu dalam proses data entry atau memasukan data (Notoatmodjo, 2013). Pemberian kode pada penelitian ini adalah sebagai berikut:

a. Jenis kelamin responden:

1. Laki-laki diberi kode 1

2. Perempuan diberi kode 2

b. Usia

1. 12-25 tahun

2. $26-45$ tahun

3. $46-65$ tahun

4. >65 tahun

c. Pendidikan

1. Pendidikan

2. SD

3. SMP

4. SMA

5. PT

d. Status Pernikahan

1. Menikah

2. Belum Menikah

3. Processing/Entry

Prosessing/entry merupakan proses memasukan data kedalam tabel dilakukan dengan program yang ada dikomputer (Setiadi, 2013). Entry dilakukan dengan bantuan program SPSS 18.

4. Cleaning

Cleaning merupakan teknik pembersiha $\mathrm{n}$ data, data yang tidak sesuai dengan kebutuhan akan dihapus (Setiadi, 2013). Apabila semua data dari setiap sumber data atau responden selesai dimasukan, perlu dicek kembali untuk melihat kemungkinan adanya kesalahan pengkodean maupun ketidaklengkapan, kemudian dilakukan pembetulan atau koreksi (Notoatmodjo, 2013). 


\section{Tehnik Analisa Data}

Hasil pengukuran dibandingkan untuk menguji hipotesis dengan menggunakan Analisa data yang digunakan adalah anilisaunivariat untuk mengetahui distribusi frekuensi dari masing-masing variabel sedangkan analisa bivariat menggunakan uji $t$ test versi 18 melaui SPSS (Standart Pengoperasin Sistem Statistik) sehingga dapat diketahui pengaruh antara variabel independen dengan dependen.

Hipotesis alternatif (Ha) diterima jika Adanya Pengaruh Teknik Relaksasi Benson Terhadap Penurunan Tingkat Stres Pada Lansia Yang Menjalani Rawat Inap Di Rumah Sakit Umum Bhayangkara TebingTinggi Tahun 2017, Hipotesis Ha di tolak (Ho) jika tidak adanya Pengaruh Teknik Relaksasi Benson Terhadap Penurunan Tingkat Stres Pada Lansia Yang Menjalani Rawat Inap Di Rumah Sakit Umum Bhayangkara Tebing-Tinggi, yang diperoleh dari hasil perhitungan uji statistik lebih $\mathrm{p}$ value> $(0,05)$.

\section{HASIL}

Hasil penelitian ini untuk mengidentifik asi Pengaruh Teknik Relaksasi Benson Terhadap Penurunan Tingkat Stres Pada Lansia Yang Menjalani Rawat Inap Di Rumah Sakit Umum Bhayangkara TebingTinggi Tahun 2017.

\section{Karakteristik Responden}

Hasil analisis data secara statistik menunjukkan bahwa ada pengaruh antara tekhnik Pengaruh Tehnik Relaksasi Benson Terhadap Penurunan Tingkat Stress Pada Lansia Yang Menjalani Rawat Inap Di Rumah SakitUmum Bhayangkara TebingTinggi.

Stres pada lansia dapat didefinisikan sebagai tekanan yang diakibatkan oleh stresor berupa perubahan-perubahan yang menuntut adanya penyesuaian dari lansia. Tingkat stres pada lansia berarti pula tinggi rendahnya tekanan yang dirasakan atau dialami oleh lansia sebagai akibat dari stresor berupa perubahan-perubahan baik fisik, mental, maupun sosial dalam kehidupan yang dialami lansia (Indriana, 2010). Beberapa faktor-faktor yang mempengaruhi stres pada lansia meliputi, kondisi kesehatan fisik, kondisi psikologi, keluarga, lingkungan, pekerjaan (Fitria, 2015)

Relaksasi Benson merupakan pengembangan metode respon relaksasi pernafasan dengan melibatkan faktor keyakinan pasien, yang dapat menciptakan suatu lingkungan internal sehingga dapat membantu pasien mencapai kondisi kesehatan dan kesejahtraan yang lebih tinggi (Benson \& Proctor 2000, dalam Purwanto, 2014).

Penelitian ini sejalan dengan pernyataan Soeharto (2009) menyatakan bahwa tujuan teknik relaksasi napas dalam adalah untuk meningkatkan ventilasi alveoli, memelihara pertukaran gas, mencegah atelektasi paru, meningkatkan efesiensi batuk, mengurangi stress baik stress fisik maupun emosional yaitu menurunkan intensitas nyeri dan menurunkan kecemasan serta menurunkan tekanan darah sistolik dan diastolic.

Penelitian ini juga sejalan dengan pernyataan Dalimartha (2008) menyatakan bahwa salah satu upaya untuk mengatasi stres adalah dengan metode relaksasi. Hal itu karna dalam relaksasi terkandung unsur penenangan diri. Teknik ini disebutnya relaksasi Benson yaitu suatu prosedur untuk membantu individu berhadapan pada situasi yang penuh stres dan usaha untuk menghilangkan stress.

\section{KESIMPULAN}

Berdasarkan hasil penelitian dapat ditarik kesimpulan bahwa adanya pengaruh tekhnik relaksasi benson sebelum dan sesudah diberikan intervensi pada lansia yang menjalani rawat inap di rumah sakiumum bhayangkara tebingtinggi.

\section{SARAN}

1. Bagi Institusi Pendidikan Kesehatan 
Hasil penelitian ini menunjukkan ada pengaruh teknik relaksasi benson terhadap tingkat stres Lansia. Selain itu, dapat juga dikembangkan dalam kurikulum mata ajar keperawatan gerontik untuk dijadikan sebagai salah satu intervensi keperawatan dalam upaya menurunkan tingkat stress lansia yang menjalani rawat inap.

2. Bagi Rumah Sakit

Hasil penelitian ini menunjukkan ada pengaruh teknik relaksasi benson terhadap tingkat stres lansia, untuk itu melalui bidang pendidikan dan latihan Rumah Sakit Bhayangkara bekerja sama dengan bidang keperawatan dipandang perlu mengembangkan program pelatihan perawat agar berkompeten di bidang tekhnik relaksasi benson.

3. Bagi Penelitian Selanjutnya

Bagi penelitian selanjutnya perlu dilakukan penelitian seperti ini kembali dengan jumlah sampel yang lebih banyak sehingga dapat memberikan power yang lebih tinggi lagi,.

\section{DAFTAR PUSTAKA}

Dalimartha, S., dkk. (2008). Care your self hipertensi. Cetakan 1. Jakarta: Penebar Plus.

Darmojo \& Martono. (2004). Buku ajar geriatri (Ilmu Kesehatan Usia Lanjut). Jakarta: FKUI.

Dempsey, P. A.\& Arthur D. D. (2002). Riset keperawatan buku ajar \& latihan. Edisi 4. Jakarta: EGC.

Fitria. (2007). Prinsip Dasar dan Aplikasi Penulisan Laporan Pendahuluan dan strategi pelaksanaan tindakan keperaw atan. Jakarta: SalembaMedika.

Handoyo. (2004). Meditasi dan Muara Hati. Jakarta: P.T Jakarta.

Henry and John. (2005). The short-form version of the Depression Anxiety Stress Scales (DASS-21): Construct validity and normative datain a large non- clinical sample. British Journal of ClinicalPsychology, 44, 227-239.

Hidayat. (2004). Model konsep dan teori keperawaan. Jakarta: EGC.

Indriani Y. (2010). Tingkat stress lansia dipanti werdha pucanggading semarang . Jurnal Psikologi Undip, Vol. 8, no. 2.

Lumbotobing. (2006). Kecerdasan pada usia lanjut dan dementia. Jakarta: FKUI.

Maryam, S, dkk. (2011). Mengenal usia lanjut \& perawatannya. Jakarta: Salemba Medika.

National Safety of Council. (2004). Manjemen stres. Jakarta: EGC.

Notoatmodjo, S. (2005). Metodologi penelitian kesehatan. Edisi Revisi. Jakarta: Rineka Cipta.

Notoatmodjo, S. (2010). Metodologi penelitian klinis. Jakarta: EGC.

Nugroho. (2000). Keperawatan gerontik. Jakarta: EGC.

Nursalam, P.S. (2008). Pendekatan praktis metodologi riset keperawatan. Jakarta: Sagung Seto.

Nursalam. (2003). Konsep \& penerapan metodologi penelitian ilmu keperawatan. Jakarta: Salemba Medika.

Patrick, Jeff and Dyck, Murray andBramston, Paul. (2010). Depression Anxiety Stress.

Potter \& Perry. (2005). Fundamental keperawatan. Edisi ke-4. Jakarta: EGC.

Prabowo, Hendro. (2007). Tritmenmeta music untuk menurunkan stress. Proceeding pesat (psikologi, ekonomi, sastra, arsitek, \&sipil) auditorium kampus gunatama, 21-22.

Purwanto, S.2006. Relaksasi dzikir. Jurnal psikologi universitas Muhammadiayah semarang, 18(1), 6-48.

Risnas, N. (2005). Pengaruh relaksasi benson terhadap pemenuhan kebutuhan tidur pada lansia. Jurnal kesehatan, 126. 